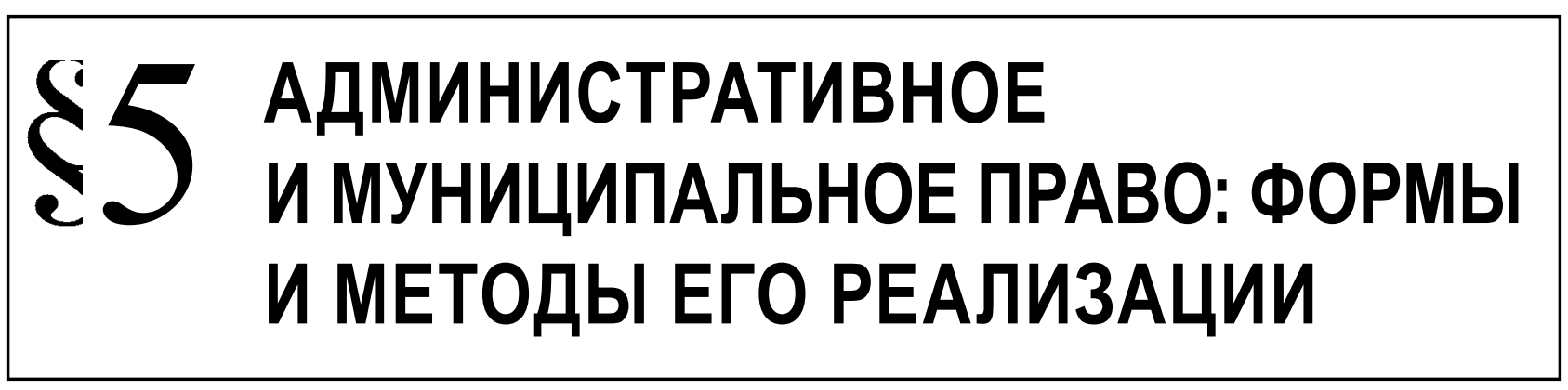

Калинина Л.Е.

\title{
ГОСУДАРСТВЕННАЯ ПОШЛИНА ПРИ ЛИЦЕНЗИРОВАНИИ: ПЛАТА ЗА ТЕХНИЧЕСКИЕ ОШИБКИ
}

Аннотация: Автор рассматривает государственную пошлину при лицензировании как комплексное правовое отношение, требующее системного регулирования. Устанавливая государственную пошлину, следует рассматривать лицензирование как публичную услугу, состоящую из набора выполняемых управленческих операций. В статье анализируются проблемы установления финансовых основ государственной пошлины, определяются юридически значимые действия, лежащие в основе установленного сбора. Автор использовал судебную практику, в том числе Постановления Конституционного суда РФ, которые относят отношения с государством к предпринимательскому риску. В процессе подготовки статьи использовались как общенаучные методы: дедукция, индукция, анализ, синтез; так и частно-научные методы исследования: историко-правовой, юридико-догматический, логический в сочетании с системным анализом исследуемых явлений, метод анализа нормативной базы и обобщение практики ее применения. Новизна состоит в теоретической разработке комплексного правового отношения по уплате государственной пошлины при лицензировании.Выводы. Комплексное правоотношение предполагает, что правовое регулирование составных частей отношения, включающих нормы финансового и административного права, будет развиваться не самостоятельно, а выстраиваться в систему, учитьвая регулирование в целом конкретного правоотношения, .

Ключевые слова: административное право, административный процесс, лицензирование, государственная пошлина, публично-правовой платеж, юридически значимое действие, государственная услуга, государственное управление, анализ законодательства, обзор судебной практики.

Review: The author considers a state duty for licensing as a complex legal relationship, requiring a system regulation. In the process of a state duty establishing, licensing should be considered as a public service consisting of a range of managerial operations. The article analyzes the problems of establishing of the grounds for a state duty, determines the legally significant actions serving as a base for the duty. The author uses the court practice, including the resolutions of the Constitutional Court of the Russian Federation, which attribute the relations with the state to entrepreneurial risk. The author uses the general scientific methods of deduction, induction, analysis and synthesis, and the special scientific research methods: the historical-legal method, the juridical-dogmatic method, the logical method with the system analysis, the method of legal base analysis and generalization of its use. The novelty of the research lies in the theoretical study of the complex legal relationship of a state duty payment for licensing. The author concludes that a complex legal relationship presupposes that the legal regulation of the parts of the relationship, including the relulations of financial and administrative law, will be developing not independently, but will be integrating in the system, taking into account the regulation of the particular legal relationship.

Keywords: administrative law, administrative trial, licensing, state duty, public payment, legally significant actions, state service, public administration, analysis of legislation, court practice review.

$Э$ кономическая деятельность требует гибкости в регулировании со стороны государства. Применяя различные публично-правовые методы, государство может влиять на развитие конкретных отраслей экономики, как в сторону прогресса, так и в сторону торможения.

Одним из применяемых методов для воздействия на современную экономику является лицен- 
зирование. В рамках предлагаемого исследования необходимо разобраться с природой отношений. Согласно ст. 3 Федерального закона от 04.05.2011 № 99-Ф3 «0 лицензировании отдельных видов деятельности» одним из элементов лицензирования является деятельность лицензирующих органов по предоставлению (переоформлению, продлению) специального разрешения на право осуществления юридическим лицом или индивидуальным предпринимателем конкретного вида деятельности ${ }^{1}$.

Из теоретических продходов к природе лицензирования наиболее полно дает определение Р.Б. Хуторецкий, рассматривая под лицензированием урегулированные нормами права общественные отношения, возникающие между компетентным государственным органом и хозяйствующим субъектом по поводу получения, продления, отзыва специального разрешения (лицензии) на занятие определенным видом деятельности, правовыми последствиями которых являются соответственно возникновение, продление или прекращение специальной правоспособности юридического лица или индивидуального предпринимателя ${ }^{2}$. Такое определение позволяет в полной мере выделить признаки лицензирования:

1) Вид общественных отношений;

2) Субъектами правоотношений являются органы исполнительной власти в рамках установленной компетенции с одной стороны, и хозяйствующие субъекты с другой стороны;

3) Содержание: разрешение на занятие определенным видом деятельности;

4) Правовые последствия: специальная правоспособность хозяйствующего субъекта в виде права заниматься определенным видом деятельности. Однако, рассматривая лицензирование как правовой метод, А.В.Воронов и И.Н. Трофименко под ним понимают деятельность соответствующих государственных органов, связанную с выдачей лицензий и контролем за соблюдением лицензионных требований ${ }^{3}$.

Разница в подходах формирует различие в целеполагании лицензирования. В первом случае ре-

\footnotetext{
1 Собрание законодательства РФ”, 09.05.2011, № 19, ст. 2716

2 Хуторецкий Р. Лицензирование в гражданском праве // Право и жизнь. 2000. № 29 // URL: www.pravogizn.h1.ru/KSN ews/PIG_28.htm

3 См.: Ласкина Н.В., Степаненко О.В. Комментарий к Федеральному закону от 04.05.2011 № 99-Ф3 “О лицензировании отдельных видов деятельности” // Подготовлен для системы КонсультантПлюс, 2011
}

зультатом является предоставленное право, а во втором - выдача лицензии.

Данные различия весьма существенны, так как необходимо определиться с природой платежа государству. И здесь важно выяснить, за что хозяйствующие субъекты должны отдать государству денежные средства: за право заниматься определенным видом деятельности или за действия государственных органов? Уяснение природы платежа приведет к вопросу финансовой обоснованности его размера.

В соответствии со ст. 333.16 Налогового кодекса РФ уплата государственной пошлины, являющейся федеральным сбором, направлена на совершение уполномоченным органом в отношении ее плательщика юридически значимых действий. Опираясь на определение Прусакова А.Д. ${ }^{4}$, будем рассматривать под юридически значимым действием получившее оценку в правовых предписаниях, внешне выраженное в движениях активное проявление воли уполномоченного органа, совершаемое с использованием определенных средств и способов, влекущее или способное повлечь юридически значимые последствия. При этом действие нацелено на реализацию правовых дозволений и обязываний. Таким образом, целью лицензирования является возникновение специальной правоспособности - права заниматься определенным видом деятельности.

Следует сказать, что законодатель при определении перечня юридически значимых действий не был последователен. Закрепленные в ст. 333.33 НК РФ действия (кроме государственной регистрации - прим. автора) можно сгруппировать следующим образом:

- Предоставление права (например, на вывоз культурных ценостей);

- Выдача разрешений, предоставление лицензий;

- Совершение действий (например, истребование документов, предварительное рассмотрение документов).

Перечисленные действия в целом представляют совокупность последовательных действий такой стадии административного процесса, как рассмотрение дела. В рамках стадии сначала происходит сбор и анализ документов и информации для принятия решения; затем принимается решение, которое имеет формальное выражение; формально определенное решение является юридическим фак-

\footnotetext{
4 Прусаков, А. Д. Действие и бездействие как формы юридически значимого поведения :Автореферат иссертации на соискание ученой степени кандидата юридических наук /А. Д. Прусаков. - Саратов,2008. -32 с.
} 
том для возникновения, изменения и прекращения юридического права.

Собственно говоря, количество управленческих операций, а значит, и стоимость, будут в каждом конкретном случае различны. Кроме того, разными будут и правовые последствия.

Так, при установлении юридически значимых действий в виде совершения действий, размер государственной пошлины должен включать стоимость следующих действий: принятие заявления, определение ответственного лица, обработка ответственным лицом документов и информации, составление и направление документов организационного характера. Данные действия не гарантируют физическому или юридическому лицу, обратившемуся в уполномоченный орган, позитивных правовых последствий: например, выясняется в ходе совершаемых действий, что субъект не может претендовать на возникновение специальной правоспособности.

При установлении юридически значимых действий в виде выдачи разрешения/лицензии, размер государственной пошлины должен включать стоимость действий предыдущего этапа, а также действий по принятию решения, оформлению лицензии (заказ и изготовление бланков лицензии, заполнение бланков, подписание и проставление печати).

И при установлении юридически значимых действий в виде предоставления права, государственная пошлина должна складываться из стоимости совершенных действий, выдаваемого разрешения и эмпирически расчитанной стоимости самого права на предоставляемый период.

С данной позиции можно говорить, во-первых, о том, что размер государственной пошлины должен расчитываться как стоимость всех операций, выполняемых в рамках юридически значимых действий. Тогда, одни и те же юридически значимые действия не могут стоить дифференцированно в зависимости от того, для кого совершаются - юридических или физических лиц. А во-вторых, при установлении государственной пошлины необходимо правильно определить само юридически значимое действие. В противном случае, субъект правоотношения будет оплачивать действия, которые уполномоченный орган в отношении него не совершает.

На практике приходится реализовать те нормы права, которые закреплены в действующем законодательстве. Так, для определения юридически значимых действий для лицензирования можно использовать либо этап выдачи лицензии, либо предоставления права. Налоговый кодекс РФ определяет такие действия моментом предоставления лицензии (ст.333.33 НК РФ). Такая формулировка позволяет сделать вывод, что в сбор включается выдача лицензии, а не предоставляемое право. Однако, анализируя разброс размера госпошлины - от 40000 до 6000000 рублей - рискнем предположить, что предоставляемое право включается.

Анализ природы правоотношений необходим для совершенствования законодательства и решения проблемных аспектов лицензирования. Самым болезненным вопросом в правоприменении является отказ в выдаче лицензии. С учетом указанных выше этапов стадии рассмотрения дела, логично считать, что отказ возможен только на этапе совершения действий, когда уполномоченный лицензирующий орган обрабатывает и анализирует представленные документы.

Однако, Налоговый кодекс РФ, устанавливая государственную пошлину за предоставление лицензии, никак не регулирует вопросы отказа в выдаче лицензии в ст. 333.40 НК РФ. Данный пробел в законодательстве позволяет судам определить следующую позицию: сбором оплачиваются действия лицензирующего органа, связанные с рассмотрением представленных документов, а не результат рассмотрения - предоставление лицензии ${ }^{5}$.

Подобная практика приводит к тому, что уполномоченные органы в административных регламентах в качестве результата оказываемой услуги по выдаче лицензии определяют выдачу (отказ в выдаче) лицензии 6 . То есть самостоятельно устраняют пробел права в сторону расширения нормы.

Здесь стоит пояснить, что развитие законодательства о лицензировании и налогового законодательства шло параллельными путями без установления системных связей. Федеральный закон от 25.09.1998 № 158-Ф3 «0 лицензировании отдельных видов деятельности» устанавливал за выдачу лицензии лицензионный сбор, ограничиваемый максимальным пределом ${ }^{7}$. При этом, следующий Федеральный закон от 08.08.2001 № 128-ФЗ «0 лицензировании отдельных видов деятельности» раз-

\footnotetext{
5 Определение ВАС РФ от 29.03.2012 № ВАС-3542/12 об отказе в передаче дела в Президиум // СПС Консультант плюс

6 Приказ Департамента потребительской сферы Краснодарского края от 28.06.2013 № 78 “Об утверждении административного регламента предоставления департаментом потребительской сферы Краснодарского края государственной услуги "Выдача лицензии на розничную продажу алкогольной продукции на территории Краснодарского края” // http://admkrai.krasnodar.ru, 02.07.2013
}

7 Собрание законодательства РФ. 1998. № 39. ст. 4857. 
граничивал лицензионный сбор за рассмотрение заявления и за предоставление лицензии (по смыслу закона - предоставление права) ${ }^{8}$.

Налоговое законодательство двигалось по пути кодификации налоговых норм и уменьшения количества налогов. Внесение в 2004 году в Налоговый кодекс РФ главы о государственной пошлине привело к отказу от использования термина «лицензионный сбор» и объединению платы за действия государственных органов (рассмотрение заявления) и платы за специальное право. А с учетом того, что унифицированные нормы о государственной пошлине установлены за разные юридически значимые действия, их особенности нормами не урегулированы. В такой ситуации применение при лицензировании юридических конструкций государственной пошлины, рассчитанных на рассмотрение дела (как, например, в судопроизводстве) недопустимо: рассмотрение дела - стадия процесса, не предполагающая изначально какого-либо результата (суд может удовлетворить требования, а может и отказать в удовлетворении).

Следует рассмотреть и практику Конституционного суда, который рассматривает государственную пошлину, взимаемую за совершение уполномоченным органом или должностным лицом соответствующих юридически значимых действий, как специфическую разновидность публично-финансовых платежей, размер которых не обязательно должен быть эквивалентен понесенным в связи с совершением этих действий затратам и определяется федеральным законодателем на основе принципов справедливости и соразмерности исходя из цели обеспечения публичного порядка в конкретной сфере общественных отношений и характера прав, реализация которых связывается с необходимостью уплаты государственной пошлины 9 . Сформулированные Конституционным судом РФ признаки государственной пошлины отрываются от истории становления законодательства о самой государственной пошлине и лицензировании и буквально толкуют существующие нормы, опираясь, при этом, на сложившуюся судебную практику.

Так, рассматривая госпошлину как публично-финансовый платеж, считаем, что она обладает всеми

\footnotetext{
8 Собрание законодательства РФ. 2001. № 33 (часть I)., ст. 3430.

9 Постановление Конституционного Суда РФ от 23.05.2013 № 11-П "По делу о проверке конституционности пункта 1 статьи 333.40 Налогового кодекса Российской Федерации в связи с жалобой общества с ограниченной ответственностью “Встреча" // Собрание законодательства РФ. 2013. № 22. ст. 2862.
}

признаками такого платежа. Например, Федеральный Конституционный Суд Германии определяет сборы (пошлины) следующим образом: «Сборами являются публично-правовые платежи, которые по причине индивидуально оказываемых публичных действий налагаются на плательщика на основе правовой нормы или иной властной меры и которые предусмотрены для того, чтобы полностью или частично покрыть связанные с этими действиями расходы» ${ }^{10}$.

Однако, Конституционный суд РФ трактует пошлину широко и отрывает ее размер от затрат на действия государственных органов. Проблема данного определения состоит в том, что в основу публичного платежа закладывается не четко выведенная формула расчета, а принципы справедливости и соразмерности. Данные принципы-идеи имеют оценочный характер и адекватны для системы правосудия, проявляясь в том или ином результате правоприменения - «в справедливом характере судебного решения, примирении конфликтующих сторон, в сдерживании антиобщественных побуждений и устремлений индивидов и групп и тем самым в обеспечении и поддержании мира, порядка, общего блага» ${ }^{11}$.

Понятие справедливости в государственном управлении традиционно отражает требование соответствия деяния и воздаяния, т. е. соответствия ценностей, благ, которые субъект деятельности (личность, социальная группа и т. д.) дает обществу (другим людям) и получает от него. По мнению А.И. Позднякова «справедливость в государственном управлении предполагает анализ соответствия решений отдельного госчиновника, управленческих структур, госаппарата управления в целом с интересами общества. Справедливость государственного управления налицо тогда, когда управленческие решения госаппарата носят общественно полезный характер, а не направлены на реализацию частных интересов» ${ }^{12}$. Для Российской Федерации это возможное будущее, а не существующая реальность.

Не полная конструкция института государственной пошлины при лицензировании позволяет рассматривать справедливым невозвращение

10 Козырин А. Н. Административное и финансовое право, 2006.

11 Вязов А. Л. Принцип справедливости в современном российском праве и правоприменении: Теоретико-правовое исследование : Автореф. дис. на соискание уч. ст. канд. юрид. наук. // Академия управления МВД России. -М.,2001. -26 c.

12 Поздняков. А.И. Конфликт справедливости и эффективности в государственном управлении (философско-методологический аспект проблемы) // Конфликт справедливости и эффективности в государственном управлении. -М,2011. 
государственной пошлины, не эквивалентной затратам государства, при отказе в выдаче лицензии - как предпринимательский риск. Однако, являясь частноправовой категорией, предпринимательский риск не может распространяться на публичные отношения в силу п.3 ст.2 Гражданского кодекса РФ.

Принимая сторону органов публичной власти, суды основываются на том, что правила лицензирования являются достаточно определенными, то есть исключают административное усмотрение и, следовательно, произвольный отказ в предоставлении лицензии. Анализ отказов в административном правоприменении позволяет усомниться в предсказуемости принимаемых решений. Так, как отказ рассматривается уклонение органов публичной власти от принятия решения (См., например, Постановление Федерального арбитражного суда Московского округа от 16 января 2013 года по делу № А40-67681/12-121-640).

Кроме того, отказ может быть основан на технических ошибках. Например, Федеральный закон №171-Ф3 «0 государственном регулировании производства и оборота этилового спирта, алкогольной и спиртосодержащей продукции и об ограничении потребления (распития) алкогольной продукции» не предусматривает обязанности заявителя предоставлять справку об отсутствии задолженности по налогам и сборам (ст. 19). Данную информацию лицензирующий орган обязан получать в рамках межведомственного взаимодействия с Федеральной налоговой службой РФ. Таким образом, складывающиеся между заявителем и лицензирующим органом при получении лицензии правоотношения не предполагают отношений между заявителем и налоговой службой. Закрепление самого межведомственного взаимодействия ст.7 Федерального закона от 27.07.2010 г. №210-Ф3 «Об организации предоставления государственных и муниципальных услуг» предполагает, что отношения с другими органами исполнительной власти лицензирующий орган выстраивает самостоятельно, без участия заявителя. Закон основывается на утверждении, что информация, предоставляемая в рамках межведомственного взаимодействия, всегда законна, и никаких отклонений по законности быть не может. Это означает, что закон не предусматривает ситуации наличия технических ошибок, связанных, например, с компьютерной обработкой информации, субъективным фактором государственных служащих. Так, п.6 ст. 7.1 Федерального закона от 27.07.2010 г. №210-Ф3 предусматривает ответственность только за непредставление (несвоевременное представление) инфор- мации, но не за ее недостоверность. На практике, недостоверная информация о наличии задолженности перед бюджетом является основанием для отказа в выдаче лицензии (см., например Постановление Пятнадцатого арбитражного апелляционного суда от 03 марта 2014 г. по делу № A32-23736/2013 ${ }^{13}$ ).

Следует учесть, что п.9 ст. 19 Федерального закона №171-Ф3 носит императивный характер, содержит исчерпывающий перечень оснований для отказа в выдаче лицензии и не предоставляет право лицензирующему органу при наличии указанных оснований дать возможность заявителю устранить выявленные нарушения. При этом, обжалование в суд действий налоговой службы не дает желаемого результата. Так как отношения по передаче информации возникает между органами исполнительной власти, заявитель не может восстановить свое нарушенное право, самостоятельно обжаловав предоставленную не ему информацию. Восстановление права и возврат уплаченной госпошлины, в данной ситуации, возможны только при признании самого отказа в выдаче лицензии незаконным.

Таким образом, несистемное внесение изменений в законодательство, регулирующее лицензионные правоотношения, привело к тому, что практическая реализация закрепленных норм является затруднительной, и, зачастую, нарушающей права субъектов предпринимательской деятельности. Этому же способствует применение к публичным отношениям частно-правовых формул.

На основании вышесказанного можно сделать следующие выводы.

Во-первых, лицензирование представляет собой совокупность последовательных действий органов публичной власти, результатом которых является возникновение специального права.

Во-вторых, госпошлину при лицензировании нельзя рассматривать в отрыве от самого лицензирования. Это комплексное правоотношение, правовое регулирование которого должно выстраиваться системно.

B-третьих, являясь публично-финансовым платежом, госпошлина должна быть однозначно определенным платежом. Объектом выступают юридически значимые действия. Закрепленные в ст. 333.33 НК РФ действия можно сгруппировать следующим образом:

- предоставление права (например, на вывоз культурных ценностей);

13 http://kad.arbitr.ru/PdfDocument/441b71ef-c83b-45779ba0-83c6431b0ed7/A32-22029-2013_20140303_Postan （дата обращения 30.04.2014 г.) 
- выдача разрешений, предоставление лицензий;

- совершение действий (например, истребование документов, предварительное рассмотрение документов).

В-четвертых, количество управленческих операций в юридически значимом действии, а значит, и стоимость, будут в каждом конкретном случае различны. Кроме того, разными будут и правовые последствия.

B-пятых, госпошлина при лицензировании должна быть разделена на две части: за рас- смотрение документов - представляет собой стоимость государственной услуги, и предоставление права - эмпирически рассчитанная стоимость предоставляемого права на определенный период.

B-шестых, публично-правовые нормы, закрепляющие административные процедуры, должны содержать положения о возможности самостоятельного устранения органами исполнительной власти технических ошибок.

\section{Библиография:}

1. Вязов А. Л. Принцип справедливости в современном российском праве и правоприменении: Теоретикоправовое исследование : Автореф. дис. на соискание уч. ст. канд. юрид. наук. // Академия управления МВД России.-М.,2001.-26 с.

2. Козырин А. Н. Административное и финансовое право, 2006.

3. Ласкина Н.В., Степаненко О.В. Комментарий к Федеральному закону от 04.05.2011 № 99-ФЗ "О лицензировании отдельных видов деятельности" // Подготовлен для системы КонсультантПлюс, 2011

4. Поздняков. А.И. Конфликт справедливости и эффективности в государственном управлении (философскометодологический аспект проблемы) // Конфликт справедливости и эффективности в государственном управлении.-М,2011.

5. Прусаков, А. Д. Действие и бездействие как формы юридически значимого поведения :Автореферат иссертации на соискание ученой степени кандидата юридических наук /А. Д. Прусаков.-Саратов,2008.-32 с.

6. Хуторецкий Р. Лицензирование в гражданском праве // Право и жизнь. 2000. № 29 // URL: www.pravogizn.h1.ru/ KSN ews/PIG_28.htm

7. Постановление Конституционного Суда РФ от 23.05.2013 № 11-П "По делу о проверке конституционности пункта 1 статьи 333.40 Налогового кодекса Российской Федерации в связи с жалобой общества с ограниченной ответственностью "Встреча" // Собрание законодательства РФ. 2013. № 22. ст. 2862.

8. Определение ВАС РФ от 29.03.2012 № ВАС-3542/12 об отказе в передаче дела в Президиум // СПС Консультант плюс

9. Приказ Департамента потребительской сферы Краснодарского края от 28.06.2013 № 78 "Об утверждении административного регламента предоставления департаментом потребительской сферы Краснодарского края государственной услуги "Выдача лицензии на розничную продажу алкогольной продукции на территории Краснодарского края" // http://admkrai.krasnodar.ru, 02.07.2013.

\section{References (transliterated):}

1. Vyazov A. L. Printsip spravedlivosti v sovremennom rossiiskom prave i pravoprimenenii: Teoretiko-pravovoe issledovanie : Avtoref. dis. na soiskanie uch. st. kand. yurid. nauk. // Akademiya upravleniya MVD Rossii.-M.,2001.-26 s.

2. Kozyrin A. N. Administrativnoe i finansovoe pravo, 2006.

3. Laskina N.V., Stepanenko O.V. Kommentarii k Federal'nomu zakonu ot 04.05.2011 № 99-FZ "O litsenzirovanii otdel'nykh vidov deyatel'nosti" // Podgotovlen dlya sistemy Konsul'tantPlyus, 2011

4. Pozdnyakov. A.I. Konflikt spravedlivosti i effektivnosti v gosudarstvennom upravlenii (filosofsko-metodologicheskii aspekt problemy) // Konflikt spravedlivosti i effektivnosti v gosudarstvennom upravlenii.-M,2011.

5. Prusakov, A. D. Deistvie i bezdeistvie kak formy yuridicheski znachimogo povedeniya :Avtoreferat issertatsii na soiskanie uchenoi stepeni kandidata yuridicheskikh nauk /A. D. Prusakov.-Saratov,2008.-32 s.

6. Khutoretskii R. Litsenzirovanie v grazhdanskom prave // Pravo i zhizn'. 2000. № 29 // URL: www.pravogizn.h1.ru/KSN ews/PIG_28.htm

7. Postanovlenie Konstitutsionnogo Suda RF ot 23.05.2013 № 11-P "Po delu o proverke konstitutsionnosti punkta 1 stat'i 333.40 Nalogovogo kodeksa Rossiiskoi Federatsii v svyazi s zhaloboi obshchestva s ogranichennoi otvetstvennost'yu "Vstrecha" // Sobranie zakonodatel'stva RF. 2013. № 22. st. 2862.

8. Opredelenie VAS RF ot 29.03.2012 № VAS-3542/12 ob otkaze v peredache dela v Prezidium // SPS Konsul'tant plyus

9. Prikaz Departamenta potrebitel'skoi sfery Krasnodarskogo kraya ot 28.06.2013 № 78 "Ob utverzhdenii administrativnogo reglamenta predostavleniya departamentom potrebitel'skoi sfery Krasnodarskogo kraya gosudarstvennoi uslugi "Vydacha litsenzii na roznichnuyu prodazhu alkogol'noi produktsii na territorii Krasnodarskogo kraya" // http:// admkrai.krasnodar.ru, 02.07.2013. 